\title{
Clinical Significance of the Transcription Factor SOX11, Cell-Cell Adhesion Protein E-cadherin and Zinc Finger Protein BCL11A in the Diagnosis of Breast Cancer
}

\author{
Salma A. Salama ${ }^{a^{*},}$ Nadia M. Hamdy ${ }^{b}$, Reham A. A. El-Shimy ${ }^{c}$, Hala O. El-Mesallamy ${ }^{\text {b,d }}$ \\ ${ }^{a}$ Department of Biochemistry, Faculty of Dentistry, British University in Egypt, Egypt \\ ${ }^{\mathrm{b}}$ Department of Biochemistry, Faculty of Pharmacy, Ain Shams University, Cairo 11566, Egypt \\ ${ }^{\mathrm{c}}$ Department of Clinical Pathology, National Cancer Institute, Cairo University, Egypt \\ ${ }^{\mathrm{b}}$ Department of Biochemistry, Faculty of Pharmacy, Sinai University (Kantara), Egypt
}

\begin{abstract}
Transcription factors (TFs) as SRY-Box transcription factor 11 (SOX11) and B-cell lymphoma/leukemia 11A (BCL11A) role in breast cancer (BC) as well as their effect on epithelial cadherin (E-cadherin) membrane protein which is a metastasis suppressor is a question that must be addressed. Among the thirty-nine BC, patients were invasive ductal carcinoma (IDC), twenty females with benign fibroadenomas and/or fibrocystic changes, and nineteen healthy control. We quantified SOX11, E-cadherin, and BCL11A serum levels in Egyptian women with BC and determined their cut-off values. The correlation between SOX11, E-cadherin, and BCL11A sera levels and cancer antigen (CA15.3), as well as carcinoembryonic antigen (CEA), were assessed and quantified by ELISA. Finally, we explored the association between SOX11, E-cadherin levels, and BCL11A as potential markers according to histo- and clinicopathological characteristics and hormone receptors. Significant increase in E-cadherin serum levels in the cancerous than the non-cancerous group $(\mathrm{P}<0.05)$. A significant decrease in SOX11 and BCL11A serum levels $(\mathrm{P}<0.05)$ was detected in the non-cancerous group than the cancerous group. In addition, a decrease in SOX11 levels was observed in the later stage of BC cases, while earlier stage BC cases were associated with an increase in SOX11. In addition to the significant positive correlation $(\mathrm{P}<0.05)$ between SOX11 and BCL11A proteins in blood suggesting a common inter-regulatory pathway. SOX11 has an excellent area under the curve (AUC) either solely or combined with CA15.3. Earlier stages in BC were associated with an increase in SOX11 serum levels $(\mathrm{P}<0.05)$.
\end{abstract}

Keywords: Adhesion proteins; E-cadherin; BCL11A; SOX11; Proto-oncogene; TNBC; Transcription factors.

*Correspondence Salma A. Salama; Department of Biochemistry, Faculty of Dentistry, British University in Egypt.

Email: salma.ahmed@bue.edu.eg

Citation | Salama SA, Hamdy NM, El-Shimy RAA, El-Mesallamy HO, 2021. Clinical Significance of the Transcription Factor SOX11, Cell-Cell Adhesion Protein E-cadherin and Zinc Finger Protein BCL11A in the Diagnosis of Breast Cancer. Arch Pharm Sci ASU 5(1): 97-110 DOI: $10.21608 / a p s .2021 .75847 .1058$

Print ISSN: 2356-8380. Online ISSN: 2356-8399.

Received 09 May 2021. Accepted 04 June 2021.

Copyright: ${ }^{\circledR} 2021$ Salama et al. This is an open-access article licensed under a Creative Commons Attribution 4.0 International License (CC BY 4.0), which permits unrestricted use, distribution, and reproduction in any medium, provided the original author(s) and source are credited.

Published by: Ain Shams University, Faculty of Pharmacy

\section{INTRODUCTION}

Breast cancer $(\mathrm{BC})$ is the most frequently diagnosed cancer among women worldwide [1]. The magnitude of the BC burden in Egypt was unknown until the Egyptian National Cancer Registry Program compiled and published its results in $2014[\mathbf{2}, \mathbf{3}]$. According to the Egyptian National Cancer Institute (NCI), Egypt registry data $\mathrm{BC}$ ranks first among tumors and invasiveductal carcinoma (IDC) is the most frequent pathological subtype [4].

$\mathrm{BC}$ has many targeted biomarker approaches to its treatment. However, it is a heterogeneous 
disease with many different outcomes, instigating the discovery of new markers that contribute to better clinical outcome assessments. During the pathogenesis of human cancer, the transcription factors (TF) are commonly deregulated that might cause loss or gain of their function [5]. Interest in targeting TFs is now gaining interest from researchers since they can be highly effective in diagnosing and treating particular malignancies, like SOX18 being an attractive target for the treatment of metastatic disease in cancer and anti-angiogenic therapy [6].

The SRY-Box transcription factor (SOX) family is one of the TF families that are involved in cell differentiation, initiation, and activation of genes [5, 7]. Researchers have implicated SOX factors in many aspects of development, including organ development, embryogenesis, sex determination, neurogenesis, and hematopoiesis $[7,8,9.10,11]$.

The SOX family has various diverse and contradictory roles especially in oncology and plays a role during cell proliferation, migration, invasion, tumor metastasis, and suppression [12, 13, 14]. Previously, researchers have found that higher cytoplasmic and nuclear SOX11 expressions are associated with low tumor size, absence of node metastasis, and earlier stages of the disease, as well as prolonged overall survival than those with lower expression [15]. SOX11 role in tumor growth regulation is highly suggested after addressing a strong nuclear expression of SOX11 in ovarian cancer and its correlation with prolonged recurrence-free survival [16].

B-cell chronic lymphocytic leukemia (CLL)/lymphoma 11 (BCL11) gene family members, including the BCL11A and BCL11B genes, are known to be involved in Hodgkin's and non-Hodgkin's B-cell lymphoma $[17,18]$. They are zinc finger proteins and transcriptional repressors normally expressed from myeloid precursor cells and encoding the cysteine two and histidine two $(\mathrm{C} 2 \mathrm{H} 2)$ gene $[\mathbf{1 9}, \mathbf{2 0}]$.

The precise role of BCL11A in $\mathrm{BC}$ remains unclear. However, researchers have found that its level is overexpressed in triple-negative breast cancer (TNBC) than in other types of BC, and low BCL11A gene was found to decrease the tumorigenicity of TNBC, produce tumors with significantly reduced sizes and decrease the clonogenic capacity of different TNBC cell lines [21]. It is noteworthy to mention that zinc fingers are suggested to be controlled and regulated by SOX TFs [22].

Zinc family protein members are characterized by flanking zinc finger groups, enabling them to bind with a specific DNA binding ability and effectively reduce E-cadherin expression levels [23]. Studying the effect of BCL11A zinc protein family members on repressing E-cadherin levels like zinc finger Ebox- binding (ZEB) proteins will be investigated in this study. E-cadherin is a membrane adhesion protein that plays a crucial role in cancer progression and may be repressed by some zinc finger protein family members that encode cysteine two and histidine two $(\mathrm{C} 2 \mathrm{H} 2)$ gene [24].

E-cadherin is responsible for cell-to-cell adhesion between epithelial cells, resulting in cell layering as well as regulating cell morphogenesis, repression of E-cadherin, and restraining its functions cause the cell-to-cell adhesion and cell integrity to fade gradually [25]. When cell integrity is impaired, E-cadherin protein leakage occurs from the cell membrane, and its serum level increases. This aids in the process of invasion and metastasis in $\mathrm{BC}$, which strongly correlates with tumor aggressiveness and epithelial-mesenchymal transition (EMT) occurs [26]. This allows E-cadherin to be considered a tumor suppressor protein against cell metastasis and cancer aggressiveness [24]. 
Since then SOX11 serum levels have not been linked to disease outcome to date. In the current study, we focus on measuring the serum level of SOX11 and assessing its correlation with BCL11A and E-cadherin cell-to-cell adhesion protein. In addition to studying their relation to BC subtypes and BC stages. The possibility that the studied TFs would affect the E-cadherin levels is also investigated. The current paper attempt to identify new molecular markers with higher sensitivity and specificity than the classical non-specific markers of the past, with the more efficient marker(s) related to earlystages diagnosis.

\section{SUBJECTS, MATERIALS, AND METHODS}

\subsection{Subjects}

The study groups were recruited from the NCI (Egypt), Cairo University. Pretreated patients who had recently been diagnosed with BC or benign cases participated in the study.

\subsubsection{Ethics Statement}

The ethical committees at the Faculty of Pharmacy, Ain Shams University approved the study protocol (code number 97-18/10/2015) and the NCI (Egypt), Cairo University (code number IRB00004025). The study was carried out by the regulations and recommendations of the Declaration of Helsinki (WMA 2013). Written informed consent was obtained from all participants.

\subsubsection{Inclusion criteria}

Women in the malignant group were (45 cases) 39 diagnosed with IDC and 6 cases with invasive lobular carcinoma (ILC) before any treatment. Their average age was 47 (ranging from 30 to 69). The benign group cases included 20 women, diagnosed with fibrocystic changes or fibroadenoma tumors and their average age was 34 (ranging from 25 to 48). About the control group, 19 women with an average age of 42 years (ranging from 30 to 60 years) were recruited.

Study subjects underwent a physical examination. Detailed medical history and anthropometric measurements were recorded.

\subsubsection{Exclusion criteria}

Exclusion criteria included males, females under 25 years of age or over 70 of age, subjects receiving any chemotherapy or radiotherapy, patients with blood disorder diseases, any cancer other than BC. Additionally, patients with incomplete data or histopathology diagnosis and patients with distant metastasis were excluded.

\subsubsection{Participants data}

Clinical data were obtained from medical records and the original pathology reports. This data was compiled in an Excel sheet.

The following data parameters were recorded and assessed: age of the patient, tumor size (defined by mammography or magnetic resonance techniques diameter $(\mathrm{mm}$ or $\mathrm{cm})$ at diagnosis), initial tumor stage, and nodal status according to the tumor size-lymph node status and metastasis (TNM) classification of the American Joint Committee on Cancer (AJCC) guidelines [27, 28].

All histopathological parameters and tumor subtypes data included in the study were assessed by pathologists and were derived from the original pathology reports found at the NCI. Cancers subtypes were diagnosed with triple standard assessment and magnetic resonance imaging (MRI) was done if required. Hormone receptor and human epidermal growth factor receptor 2 (HER2) statuses were determined in the core biopsy through immunohistochemistry. Breast imaging-reporting and data system (BIRADS) classification were performed according to the American College of Radiology guidelines [29]. Specialized pathologists who 
have performed scoring at Cairo University and NCI Pathology Department. These scorings were made according to standardized protocols and the pathologist was unaware of the study objective.

\subsection{Blood samples collection and preparation}

Peripheral blood samples were withdrawn from patients at the end of the clinical examination interview. Blood samples were divided into two aliquots, the routine work analyses were measured on the same day of blood collection and the remaining samples were kept at $-80{ }^{\circ} \mathrm{C}$ until the time of the ELISA assays by the microplate reader (Sunrise, Tecan, Switzerland).

\subsection{Biochemical analysis}

Liver enzymes and kidney function tests (Spectrum, Hannover, Germany), were determined by spectrophotometric measurements. ELISA was used to determine serum levels of the investigated markers SOX11 (catalog No. H7362), E-cadherin (catalog No. 10036), and BCL11A (catalog No. B7679) (Glory Science Co., Ltd, China). These serum level tests were conducted in addition to CA15.3 (catalog No.EIA-5068) and CEA (catalog No. EIA-1868) (DRG, Germany), according to the manufacturers' instructions.

\subsection{Statistical analysis}

We conducted all statistical analyses using the SPSS statistical package for Windows Version 23.0 (SPSS Software, Chicago, IL, USA). The normal distribution of the data was analyzed; continuous variables were expressed as mean \pm (Standard error of the mean) (SEM) using a oneway analysis of variance (ANOVA) test. The median (interquartile range) (IQR) for the nonparametric data using the Mann- Whitney U test and Kruskal-Wallis $\mathrm{H}$ test was also used. The best cut-off values were calculated (the value with the highest sensitivity and lowest 1- specificity with the minimum difference between sensitivity and specificity) from the AUC that was obtained from the receiver operating characteristic (ROC) curve for the investigated parameter(s) (SOX11, E-cadherin, and BCL11A) (30). Correlations were assessed using the Spearman correlation coefficient ( $\mathrm{r}$ ) and P-values $<0.05$ were considered statistically significant.

\section{RESULTS}

\subsection{Clinical and biological analysis of study populations for control, benign and malignant groups}

CA15.3 and CEA as well as the studied parameters (SOX11, E-cadherin, and BCL11A), showed a significant difference among control, benign, and malignant groups (Table 1). There was a significant median difference in SOX11 levels between the malignant $(135 \mathrm{pg} / \mathrm{mL})$ and benign $(234 \mathrm{pg} / \mathrm{mL})$ groups $(\mathrm{P}<0.05)$ and between malignant $(135 \mathrm{pg} / \mathrm{ml})$ and control groups $(257 \mathrm{pg} / \mathrm{mL})(\mathrm{P}<0.05)$. Moreover, there was a significant median difference in E-cadherin between malignant $(4284 \mathrm{pg} / \mathrm{mL})$ and benign group $(3880 \mathrm{pg} / \mathrm{mL})$ at $\mathrm{P}<0.05$ and between malignant $(4284 \mathrm{pg} / \mathrm{mL})$ and control group (3403 $\mathrm{pg} / \mathrm{mL})$ at $\mathrm{P}<0.05$. The significant mean difference in BCL11A between the malignant $(9583 \mathrm{pg} / \mathrm{mL})$ and control $(10820 \mathrm{pg} / \mathrm{mL})$ groups at $\mathrm{P}<0.05$ (Table 1).

\subsection{For cancerous and non-cancerous groups}

Table 2 revealed the SOX11 median level in the cancerous $(135 \mathrm{pg} / \mathrm{L}$ and the non-cancerous groups $(239 \mathrm{pg} / \mathrm{mL})$ with a significant difference between the groups. Also, a significant median difference in E-cadherin between cancerous (4284 pg/mL) and non-cancerous groups (3542 $\mathrm{pg} / \mathrm{mL}) \quad(\mathrm{P}<0.05)$ was recorded. There was a significant mean difference for the protooncogene BCL11A between cancerous (9583 $\mathrm{pg} / \mathrm{mL})$ and $(10463 \mathrm{pg} / \mathrm{mL})$ for the noncancerous groups. 
Table 1. Clinical and biological analysis of the studied parameters in control, benign and malignant groups

\begin{tabular}{|c|c|c|c|c|c|c|}
\hline Groups (n)/ Parameters & Control (19) & Benign (20) & $\mathbf{P 1}$ & Malignant (45) & $\mathbf{P 2}$ & P3 \\
\hline Age (years) & $42(1.7)$ & $34(1.7)$ & 0.011 & $47(1.2)$ & NS & $<0.001$ \\
\hline $\mathrm{AST}^{*} \mathrm{U} / \mathrm{mL}$ & $18(14-20)$ & $17(13-27.5)$ & NS & $18(14-24)$ & NS & NS \\
\hline $\mathrm{ALT}^{*} \mathrm{U} / \mathrm{mL}$ & $16(11-21)$ & $13.5(10-19.5)$ & NS & $18(12.5-24)$ & NS & NS \\
\hline Urea* mg/dL & $23(19-26)$ & $22(20-29)$ & NS & $24(19-28.5)$ & NS & NS \\
\hline Creatinine $\mathrm{mg} / \mathrm{dL}$ & $0.64(0.03)$ & $0.61(0.03)$ & NS & $0.65(0.22)$ & NS & NS \\
\hline $\mathrm{CA} 15.3 * \mathrm{U} / \mathrm{mL}$ & $18(14.6-22)$ & $17.4(14-20.3)$ & NS & $27.6(22.7-31.3)$ & $<0.001$ & $<0.001$ \\
\hline $\mathrm{CEA}^{*} \mathrm{ng} / \mathrm{mL}$ & $0.58(0.38-0.74)$ & $0.76(0.52-1.02)$ & NS & $0.91(0.48-1.3)$ & 0.007 & NS \\
\hline SOX11* pg/mL & $257(213.8-265.3)$ & $234.7(205-323.2)$ & NS & $135(90-151)$ & $<0.001$ & $<0.001$ \\
\hline E-Cadherin* pg/mL & 3403 (2757-3804) & $3880(2495-3880)$ & NS & $4284(3804-4851)$ & 0.02 & 0.02 \\
\hline BCL11A pg/mL & $10820(239)$ & 10124 (249) & NS & $9583(235.6)$ & 0.004 & NS \\
\hline
\end{tabular}

Data are expressed as mean \pm SEM for normally distributed data, *Data are expressed as median with $25 \%$ to $75 \%$ interquartile range, P1 for significance level of benign vs control group, P2 for significance level of malignant vs control group, P3 for significance level of malignant vs benign group, Ns: Non-significant

Table 2. Non-cancerous and cancerous clinical and biological analysis

\begin{tabular}{lccc}
\hline Parameters/ Groups (n) & Non-cancerous (39) & Cancerous (45) & P value \\
\hline Age (years) & $38(1.3)$ & $47(1.2)$ & $<0.001$ \\
AST* U/mL & $18(13-24)$ & $18(14-24)$ & $\mathrm{Ns}$ \\
$\mathrm{ALT}^{*} \mathrm{U} / \mathrm{mL}$ & $15(10-20)$ & $18(12.5-24)$ & $\mathrm{Ns}$ \\
Urea* mg/dL & $22(19-29)$ & $24(19-28.5)$ & $\mathrm{Ns}$ \\
Creatinine mg/dL & $0.63(0.23)$ & $0.65(0.22)$ & $\mathrm{Ns}$ \\
CA15.3* U/mL & $17.5(14.5-20.3)$ & $27.6(22.7-31.3)$ & $<0.001$ \\
CEA* ng/mL & $0.7(0.42-0.89)$ & $0.91(0.48-1.3)$ & 0.029 \\
SOX 11* pg/mL & $239(217-332)$ & $135(90-151)$ & $<0.001$ \\
E-Cadherin* pg/mL & $3542(2757-3880)$ & $4284(3804-4851)$ & 0.004 \\
BCL11A pg/mL & $10463(180)$ & $9583(235.6)$ & 0.005 \\
\hline
\end{tabular}

Data are expressed as mean \pm SEM for normally distributed data, *Data are expressed as median with $25 \%$ to $75 \%$ interquartile range, Ns: Non-significant 


\subsection{ROC curve for the studied parameters}

ROC curves are plotted in Fig. 1 to 5 to illustrate the diagnostic capacity of the studied markers, single and combined. The cut-off point for SOX11 (Fig. 1) was set at $162 \mathrm{pg} / \mathrm{mL}$ where we achieved a sensitivity of $84 \%$ as well as a specificity of $87 \%$. The AUC was 0.91 and the $95 \% \mathrm{CI}$ was 0.84 to 0.97 and $\mathrm{P}<0.05$. The cut-off point for E-cadherin (Fig. 2) was set at 3973 $\mathrm{pg} / \mathrm{ml}$ where we achieved $71 \%$ sensitivity and $79.5 \%$ specificity. The AUC was 0.68 and the $95 \%$ CI was 0.56 to 0.8 at a $\mathrm{P}<0.05$. The best cutoff point for BCL11A (Fig. 3) was set at 9960 $\mathrm{pg} / \mathrm{ml}$ where we achieved $42 \%$ sensitivity and $38.5 \%$ specificity, with the AUC being 0.36 and also $95 \%$ CI 0.24 to 0.47 and $\mathrm{P}<0.05$.

The cut-off point of CA15.3 (Fig. 4) was set at $21 \mathrm{U} / \mathrm{mL}$ where we achieved $80 \%$ sensitivity and $79.5 \%$ specificity at a $\mathrm{P}<0.05$. The AUC was 0.89 and the $95 \%$ CI was 0.81 to 0.95 . An increase in the AUC of CA15.3 from 0.89 to 0.93 after incorporation with SOX11 marker (Fig. 5) was observed, in addition to an increase in sensitivity from $80 \%$ to $91 \%$, specificity from $79.5 \%$ to $89 \%$, and $\mathrm{P}<0.05$.

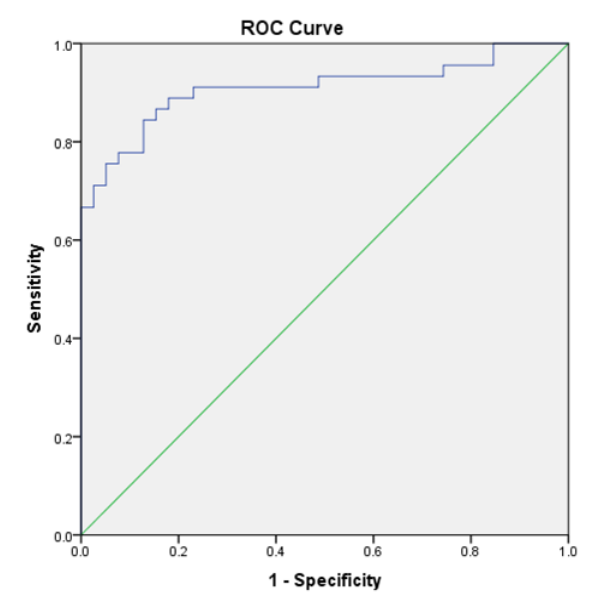

Fig 1. ROC curve for SOX11

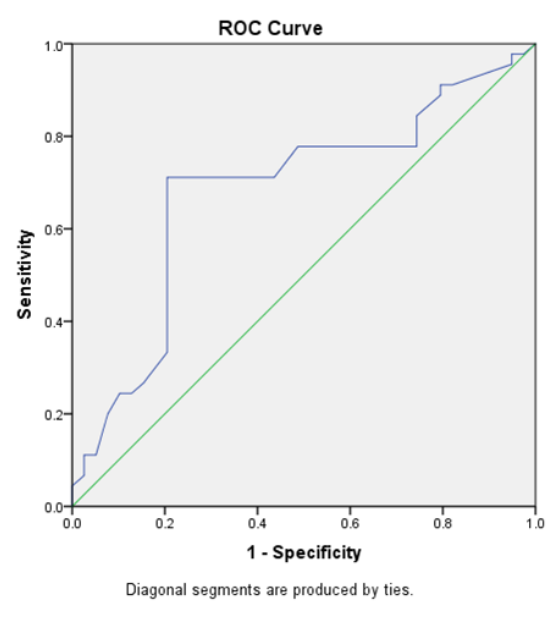

Fig 2. ROC curve for E-cadherin



Fig 3. ROC curve for BCL11A

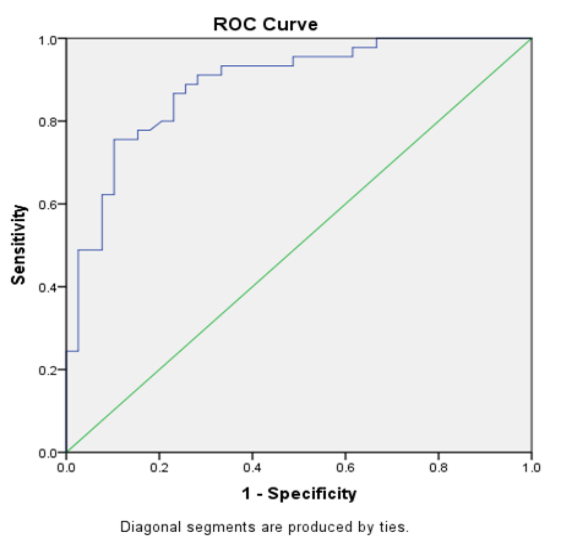

Fig 4. ROC curve for CA15.3 


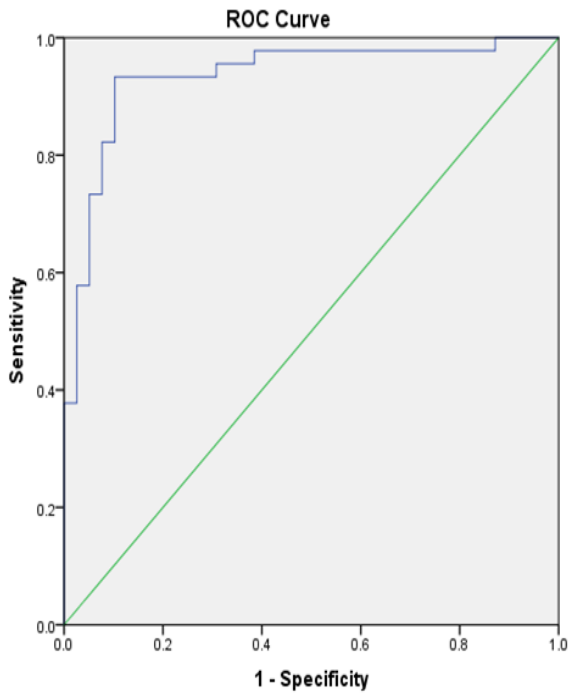

Fig 5. ROC curve for CA15.3 and SOX11

3.4. Association between the studied parameters and TNM staging among BC patients
It was found that there was a significant difference in the mean elevated serum levels of SOX11 in stage II BC cases compared to stage III $\mathrm{BC}$ cases at $\mathrm{P}<0.05$ (Table 3). However, there is no significant difference between the different tumor sizes T1-T2 $\leq 5 \mathrm{~cm}$ and $\mathrm{T} 3-\mathrm{T} 4 \geq 5 \mathrm{~cm}$ as well as node metastasis N0 and $\geq$ N1 for SOX11, E-cadherin, and BCL11A.

3.5. Association between the studied parameters, histopathological grades, and types of $\mathrm{BC}$

For the different subtypes of BC, no significant difference in serum level was observed for SOX11 and BCL11A. Among the luminal A subtype, the median level of Ecadherin was significantly elevated in comparison to the median E-cadherin serum level among the TNBC subtype at $\mathrm{P}<0.05$ (Table 4).

Table 3. Association of the studied parameters among BC patients and TN Staging

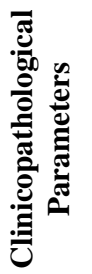

Pathological T stage, P1 Ns

Lymph Node, P2Ns

TNM Stage, P3 \#

$\mathrm{T} 1-\mathrm{T} 2 \leq 5 \mathrm{~cm} \quad \mathrm{~T} 3-\mathrm{T} 4 \geq 5 \mathrm{~cm}$

No

$\geq \mathbf{N} 1$

II

III

\begin{tabular}{|c|c|c|c|c|c|c|}
\hline $\mathrm{N}$ & 20 & 25 & 15 & 30 & 26 & 19 \\
\hline $\mathrm{SOX} 11 * \mathrm{pg} / \mathrm{mL}$ & $135(92-182)$ & $121(91-143)$ & $135(106-155)$ & $112(77-151)$ & $147(103-181)$ & $106(77.7-135)^{\#}$ \\
\hline $\begin{array}{l}\text { E-Cadherin } \\
* \mathrm{pg} / \mathrm{mL}\end{array}$ & $\begin{array}{l}4284 \\
5113)\end{array}$ & $\begin{array}{l}4284 \\
4458)\end{array}$ & $\begin{array}{c}4284(4066- \\
5375)\end{array}$ & $\begin{array}{c}4284(3018- \\
4524)\end{array}$ & $\begin{array}{c}4284(2953- \\
5113)\end{array}$ & $\begin{array}{c}4284(4284- \\
4590)\end{array}$ \\
\hline BCL11A pg/mL & 9461 (397) & $9680(287)$ & 9495 (324) & 9627 (317) & $9640(333)$ & $9505(330)$ \\
\hline
\end{tabular}

Data are expressed as mean $\pm(\mathrm{SEM})$ for normally distributed data, *Data are expressed as median with $25 \%$ to $75 \%$ interquartile range, Ns: Non-significant, \# is $P 3$ significance level at $<0.05$ 
Table 4. Association between the studied parameters among BC patients' histopathological grades and types of BC

\begin{tabular}{|c|c|c|c|}
\hline Parameters & SOX11* median (IQR) & E-Cadherin* median (IQR) & BCL11A mean (SE) \\
\hline Tumor Grade 2 vs Grade 3 & $135(95-161)$ & $4284(3804-5375)$ & $9541(270)$ \\
\hline$n(34 \mathrm{vs} 11)$ & $101(91-140)$ & $4284(2757-4284)$ & $9713(503)$ \\
\hline Luminal A vs Luminal B & $135(106-148)$ & $4384(4284-5375)$ & $9490(322)$ \\
\hline$n(24 v s 8)$ & $98(80-175)$ & $4175(2364-4284)$ & $9362(624)$ \\
\hline Luminal A vs Herceptin & $135(106-148)$ & $4384(4284-5375)$ & $9490(322)$ \\
\hline$n(24 v s 7)$ & $74(71-141)$ & $4284(3804-4284)$ & $9314(565)$ \\
\hline Luminal A vs TNBC & $135(106-148)$ & $4384(4284-5375)^{\#}$ & $9490(322)$ \\
\hline$n(24 v s 6)$ & $133(85-187)$ & $3411(2560-3935)^{\#}$ & $10550(486)$ \\
\hline Luminal B vs Herceptin & $98(80-175)$ & $4175(2364-4284)$ & $9362(624)$ \\
\hline$n(8 v s 7)$ & $74(71-141)$ & $4284(3804-4284)$ & $9314(565)$ \\
\hline Luminal B vs TNBC & $98(80-175)$ & $4175(2364-4284)$ & $9362(624)$ \\
\hline$n(8 v s 6)$ & $133(85-187)$ & $3411(2560-3935)$ & $10550(486)$ \\
\hline Herceptin vs TNBC & $74(71-141)$ & $4284(3804-4284)$ & $9314(565)$ \\
\hline$n(7 v s 6)$ & $133(85-187)$ & $3411(2560-3935)$ & $10550(486)$ \\
\hline
\end{tabular}

Data are expressed as mean $\pm(\mathrm{SEM})$ for normally distributed data, *Data are expressed as median with $25 \%$ to $75 \%$ interquartile range, Ns: Non-significant, $\# P$ is significant level at $<0.05$

Table 5. Spearman correlations between studied parameters in the $\mathrm{BC}$ group $(n=45)$

\begin{tabular}{|c|c|c|c|c|c|}
\hline Parameters & CEA ng/mL & CA15.3 U/mL & SOX11 pg/mL & E-Cadherin pg/mL & BCL11A pg/mL \\
\hline \multicolumn{6}{|l|}{ CEA ng/mL } \\
\hline $\mathrm{r}$ & & 0.245 & -0.056 & 0.068 & -0.078 \\
\hline $\mathrm{P}$ & & Ns & Ns & Ns & Ns \\
\hline \multicolumn{6}{|c|}{ CA $15.3 \mathrm{U} / \mathrm{mL}$} \\
\hline $\mathrm{r}$ & 0.245 & & -0.35 & -0.22 & -0.256 \\
\hline $\mathrm{P}$ & $\mathrm{Ns}$ & & $0.019^{*}$ & Ns & Ns \\
\hline \multicolumn{6}{|c|}{ SOX11 pg/mL } \\
\hline $\mathrm{r}$ & -0.056 & -0.35 & & -0.05 & 0.436 \\
\hline $\mathrm{P}$ & Ns & $0.019^{*}$ & & Ns & $0.003^{*}$ \\
\hline \multicolumn{6}{|c|}{ E-Cadherin pg/mL } \\
\hline $\mathrm{r}$ & 0.06 & -0.22 & -0.05 & & -0.14 \\
\hline $\mathrm{P}$ & Ns & $\mathrm{Ns}$ & Ns & & Ns \\
\hline \multicolumn{6}{|c|}{ BCL11A pg/mL } \\
\hline $\mathrm{r}$ & -0.078 & -0.256 & 0.436 & -0.14 & \\
\hline$P$ & $\mathrm{Ns}$ & Ns & $0.003^{*}$ & Ns & \\
\hline
\end{tabular}




\subsection{Correlations analysis of the studied parameters}

Investigation of serum correlations between continuous parametric (BCL11A) and nonparametric assays (CEA, CA15.3, SOX11, and Ecadherin) revealed a significant negative correlation between CA15.3 and SOX11 at $\mathrm{P}<0.05$. A significant positive correlation was observed between SOX11 and BCL11A P $<0.05$ (Table 5).

\section{DISCUSSION}

The current paper attempted to measuring SOX11 serum levels in healthy and diseased subjects as it is one of the main research objectives. However, a previous study showed that normal cells are enriched with silencing histone marks on the SOX11 promoter, which has a low degree of methylation [31]. Nonetheless, malignant cells have a high degree of methylation, which correlates inversely with SOX11 gene expression levels, proving a diverse pattern in promoter methylation of SOX11 in the cases of solid tumors compared with Blymphomas [31].

SOX11 promoter methylation can proceed (or not persist) despite protein expression. A study on epithelial ovarian cancer cell lines reveals that highly induced methylated cells correlate with a complete lack of SOX11 expression at both mRNA and protein levels [32]. This has also been observed among nasopharyngeal carcinomas [33].

Perhaps in breast tumor-genesis, there might be overexpression of SOX11 gene or upregulation first, followed by promoter methylation then down-regulation of SOX11 gene and protein expression. This would explain the lower serum levels of SOX11 among malignant subjects in comparison to healthy controls. This finding means that further research on the expression levels of SOX11 and its correlations with other tumor subtypes and the promoter methylation status is needed.

SOX11 serum levels were significant with tumor stages, as higher serum median levels were observed in stage 2 in comparison to stage 3 . SOX11 serum levels were also associated with smaller tumor size and the absence of node metastasis. In concordance with the general data, the overexpression of SOX11 correlates with a better prognosis for breast, ovarian and gastric cancers $[15,16,34]$.

Spearman's correlation significantly showed a negative correlation between SOX11 and CA15.3. This relationship reinforces the suggestion that higher expression of SOX11 is associated with better disease outcomes and earlier tumor stages.

SOX11 silencing inhibits apoptosis by inhibiting caspase-9-3-7-PARP signaling and desensitizing mantle cell lymphomas to the anticancer drugs [35]. Also, SOX11 is negatively regulating autotaxin levels which promotes tumor growth and survival in cells involved with carcinogenesis [36]. SOX11 silencing decreases cell cycle protein regulators, promoting G1 phase conversion to the $S$ phase [35]. All these effects may increase tumor aggressiveness and cancer burden when the SOX11 level is decreased in BC patients.

The tumor suppressor functions of SOX11 are supported by the tumor suppressor functions of SOX families through blocking the Wnt/catenin signaling pathway and the invasion-related genes [37].

The loss in E-cadherin expression was found to be associated with metastasis and lobular carcinomas in comparison to IDC carcinoma [38]. Loss of E-cadherin and the resulting suppression or impairment of cell-to-cell adhesion causing protein leakage from the membrane and its rise in serum levels, and E- 
cadherin loss gradually contributes to metastasis and initiation of the primary steps in the EMT process in cancer patients in agreement with public data [39]. EMT is the coordinated destabilization of cell-to-cell contacts and the acquisition of a more migratory and invasive mesenchymal phenotype $[\mathbf{2 4 , 4 0 ]}$.

Regarding the diagnostic utility of serum Ecadherin to differentiate between cancerous from non-cancerous cases, the ROC curve was plotted with an AUC of 0.68 which is a fair AUC. Therefore, E-cadherin can be used combined with SOX11 or with conventional markers such as CA15.3 and is not used solely, to improve allusefulness in $\mathrm{BC}$ diagnosis.

Comparing the use of a fixed cut-off value, serum SOX11 has an excellent AUC of 0.91. SOX11 can be used to diagnose and differentiate between cancerous and non-cancerous cases. This raises the possibility that this parameter can be used as a strong diagnostic marker either solely or combined with one of the specific markers such as CA15.3. Combining SOX11 with CA15.3 increased the AUC from 0.89 (CA15.3) to 0.93 (combined), sensitivity, and specificity of the diagnosis. All these previous values were obtained and showed an improvement of the diagnostic utility than using CA15.3 alone.

By stratifying patients in the malignant group, according to $\mathrm{BC}$ subtypes, a significant difference in E-cadherin levels in luminal $\mathrm{A}$ and TNBC subtypes was observed. This is suggested to be due to the increase in the levels of BCL11A in the TNBC group. High levels of BCL11A might decrease the intracellular expression levels of E-cadherin. BCL11A shares the same gene family of ZEB proteins ( $\mathrm{C} 2 \mathrm{H} 2$ type) which can hypothetically share a similar mechanism on Ecadherin repression [23].

In the current study, E-cadherin levels were not significant when groups were stratified by tumor stages in agreement with public data [41, 42]. However, reduction of E-cadherin expression is associated with a poor prognosis [43].

E-cadherin likely has a more diagnostic function in differentiating between cancerous and non-cancerous groups and between metastatic and non-metastatic groups, rather than differentiating between stages of BC. Spearman's correlation showed no serum correlation between E-cadherin and either CEA or CA15.3 serum levels.

Significant serum BCL11A mean levels difference between cancerous and non-cancerous subjects suggests a process of down-regulation to BCL11A during the occurrence process of malignancy. This is despite the TNBC breast subtype was associated with higher BCL11A mean levels, than the non-cancerous group. This could justify the aggressiveness of this BC subtype. No significant differences in BCL11A and the histopathological characteristics were observed. The mean level of BCL11A was highest in TNBC and lowest in the Herceptin BC subtype.

Both SOX11 and BCL11A are expressed from lymphoid tissues [44, 45]. Both have been found to regulate the B-cell-specific activator protein (pax5) the protein responsible for the early B-cell differentiation stage $[46,47]$. The significant positive correlation between SOX11 and BCL11A proteins in the blood might suggest a common regulatory pathway of the two proteins (markers) to be explored.

This is further supported by the reactivation of the embryonic developmental programs in mature mammary breast cells with mouse Breast Cancer Gene (BRCA1 -/-) deleted or mutated gene. In these mammary breast cells, SOX11 and BCL11A are activated along with other TFs [48]. 
Study findings are revealed in Fig. 6 illustrating the most important results.

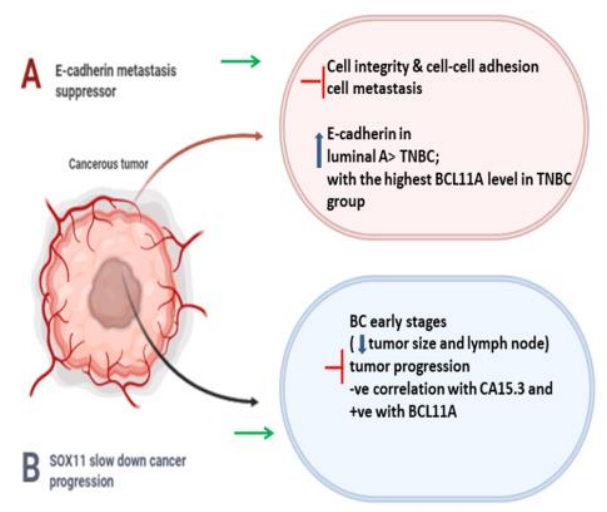

Fig 6. A Collective Illustrative Diagram

\section{Conclusion}

This study showed a significant elevation in E-cadherin serum levels in cancerous subjects. However, there was also a significant decrease in SOX11 and BCL11A serum levels in this BC study group. An increase in serum SOX11 levels was associated with earlier stages of BC. Serum SOX11 has an excellent AUC and can be used either solely or combined with CA15.3 to improve $\mathrm{BC}$ diagnosis. E-cadherin can be used combined with SOX11 or with conventional markers such as CA15.3 and not being used solely. E-cadherin levels can aid as a diagnostic marker in breast carcinomas. BCL11A has no significant role in all BC subtypes. TNBC breast subtype was associated with a higher protooncogene BCL11A mean level than the noncancerous group.

\section{List of abbreviations}

AUC, Area Under the Curve; BC, Breast Cancer; BCL11A, B cell Lymphoma/Leukemia 11A; CA15.3, Cancer Antigen 15.3; CEA, Carcino-Embryonic Antigen; $\mathrm{C} 2 \mathrm{H} 2$, Cysteine two and Histidine two; E-cadherin: Epithelial Cadherin; EMT, Epithelial-to-Mesenchymal Transition; IDC, Invasive Ductal Carcinoma,
ILC, Invasive Lobular Carcinoma; NCI, National Cancer Institute; SOX, SRY-Box Transcription Factor 11; TFs, Transcription Factors; TNBC, Triple-Negative Breast Cancer; TNM, Tumor size-Lymph node-Metastasis; ZEB, Zinc Finger E-Box- Binding.

\section{Study Limitations}

These findings are specific to pre-treated subjects and cannot be generalized to post-treated subjects. Despite the limited number of subjects enrolled in this study, the results can still guide further research studies.

\section{Recommendations and future directions}

Study of the relation of the promoter methylation status; epigenetic modification and SOX11 expression.

\section{Declarations}

Ethics approval and consent to participate

Not applicable

\section{Consent to publish}

Not applicable

\section{Availability of data and materials}

The data generated or analyzed during this study all are included in the main manuscript.

\section{Conflict of interest}

The authors declare that there is no conflict of interest.

\section{Funding}

This research did not receive any specific grant from funding agencies in the public, commercial, or not-for-profit sectors.

\section{REFERENCES}

1. Bray F, Ferlay J, Soerjomataram I, Siegel RL, Torre LA, Jemal A. Global cancer statistics 2018: GLOBOCAN estimates of incidence and mortality worldwide for 36 cancers in 185 countries. CA 
Cancer J Clin. 2018; 68(6):394-424. doi: 10.3322/caac.21492.

2. Ibrahim AS, Khaled HM, Mikhail NN, Baraka H, Kamel H. Cancer incidence in Egypt: results of the national population-based cancer registry program. J Cancer Epidemiol. 2014; 2014:437971. doi: 10.1155/2014/437971. Epub 2014 Sep 21.

3. Ibrahim AS. and Nazmi N. Cancer: The Growing Monster in Egypt. Cancer Prev Curr Res. 2016; 6(4):00217. doi: 10.15406/jcpcr.2016.06.00217.

4. Farouk O, Ebrahim MA, Seibel A, Emarah Z, Abozeed W, Seisa MO, et al. Breast cancer characteristics in very young Egyptian women $\leq 35$ years. Breast Cancer 2016; 8:53-58. doi: 10.2147/BCTT.S99350.

5. Tsang SM, Oliemuller E, Howard BA. Regulatory roles for SOX11 in development, stem cells, and cancer. Semin Cancer Biol. 2020; 67(1):3-11. doi: 10.1016/j.semcancer.2020.06.015.

6. Grimm D, Bauer J, Wise P, Kruger M, Simonsen U, Wehland $\mathrm{M}$, et al. The role of SOX family members in solid tumors and metastasis. Semin Cancer Biol. 2020; 67(1):122-153. doi: 10.1016/j.semcancer.2019.03.004. Epub 2019 Mar 23.

7. Bergsland M, Ramskold D, Zaouter C, Klum S, Sandberg R, Muhr J. Sequentially acting Sox transcription factors in neural lineage development. Genes Dev. 2011; 25(23):2453-2464. doi: 10.1101/gad.176008.111. Epub 2011 Nov 15

8. Nakajima-Takagi Y, Osawa M, Oshima M, Takagi $\mathrm{H}$, Miyagi S, Endoh M et al. Role of SOX17 in hematopoietic development from human embryonic stem cells. Blood. 2013; 121(3):447458. doi: 10.1182/blood-2012-05-431403. Epub 2012 Nov 20.

9. Ji EH, Kim J. SoxD Transcription Factors: Multifaceted Players of Neural Development. Int J Stem Cells. 2016; 9(1):3-8. doi: 10.15283/ijsc.2016.9.1.3

10. Janssen R, Andersson E, Better E, Bijl S, Fowler W, Hook L, et al. Embryonic expression patterns and phylogenetic analysis of panarthropod sox genes: insight into nervous system development, segmentation, and gonadogenesis. BMC Evol Biol. 2018;18(1):88. doi: 10.1186/s12862-018-1196-z.

11. Li Y, Struebing FL, Wang J, King R, Geisert EE. Different Effect of Sox11 in Retinal Ganglion Cells Survival and Axon Regeneration. Front Genet. 2018; 18;9:633. doi: 10.3389/fgene.2018.00633. eCollection 2018

12. Huang HY, Cheng YY, Liao WC, Tien YW, Yang $\mathrm{CH}$, Hsu SM, et al SOX4 transcriptionally regulates multiple SEMA3/plexin family members and promotes tumor growth in pancreatic cancer. PLoS One. 2012;7(12):e48637. doi: 10.1371/journal.pone.0048637. Epub 2012 Dec 12.

13. Yin D, Jia Y, Yu Y, Brock MV, Herman JG, Han C, Su X, Liu Y, Guo M. SOX17 methylation inhibits its antagonism of Wnt signaling pathway in lung cancer. Discov Med. 2012; 14(74):33-40

14. Tong X, Li L, Li X, Heng L, Zhong L, Su X et al. SOX10, a novel HMG-box-containing tumor suppressor, inhibits growth and metastasis of digestive cancers by suppressing the $\mathrm{Wnt} / \beta$-catenin pathway. Oncotarget 2014; 5(21):10571-10583. doi: 10.18632/oncotarget.2512.

15. Liu DT, Peng-Zhao, Han JY, Lin FZ, Bu XM, Xu QX. Clinical and prognostic significance of SOX11 in breast cancer. Asian Pac J Cancer Prev. 2014; 15(13):5483-5486. doi: 10.7314/apjcp.2014.15.13.5483

16. Brennan DJ, Ek S, Doyle E, Drew T, Foley M, Flannelly G, et al. The Transcription Factor SOX11 is a Prognostic Factor for Improved Recurrence-Free Survival in Epithelial Ovarian Cancer. Eur J Cancer 2009;45(8):1510-1517. doi: 10.1016/j.ejca.2009.01.028. Epub 2009 Mar 9.

17. Satterwhite E, Snooki T, Willis TG, Harder L, Nowak R, Arriola EL, et al. The BCL11 gene family: involvement of BCL11A in lymphoid malignancies. Blood 2001; 98(12):3413-3420. doi: 10.1182/blood.v98.12.3413.

18. Shi H, Li C, Feng W, Yue J, Song J, Peng A et al. BCL11A Is Oncogenic and Predicts Poor Outcomes in Natural Killer/T-Cell Lymphoma. Front. Pharmacol. 2020; 11:820. doi: 
10.3389/fphar.2020.00820.

19. Sankaran VG, Menne TF, Xu J, Akie TE, Lettre G, Van Handel B, et al. Human fetal hemoglobin expression is regulated by the developmental stage-specific repressor BCL11A. Science. 2008; 322(5909):1839-1842. doi: 10.1126/science.1165409. Epub 2008 Dec 4.

20. Holmes RS, Cox LA. Comparative studies of glycosylphosphatidylinositol-anchored highdensity lipoprotein-binding protein 1: evidence for a eutherian mammalian origin for the GPIHBP1 gene from an LY6-like gene. 3 Biotech. 2012; 2(1):37-52. doi: 10.1007/s13205-011-00264. Epub 2011 Oct 18.

21. Khaled WT, Choon Lee S, Stingl J, Chen X, Raza Ali H, Rueda OM, et al. BCL11A is a Triple Negative BC gene with critical functions in stem and progenitor cells. Nat Commun 2014; 6:5987. doi: $10.1038 /$ ncomms6987.

22. Sha L, Kitchen R, Porteous D, Blackwood D, Muir W, Pickard B. SOX11 target genes: implications for neurogenesis and neuropsychiatric illness. Acta Neuropsychiatr. 2012; 24(1):16-25. doi: 10.1111/j.1601-5215.2011.00583.x .

23. Wong TS, Gao W, Chan JY. Transcription regulation of E-cadherin by zinc finger E-box binding homeobox proteins in solid tumors. Biomed Res Int. 2014; 2014:921564. doi: 10.1155/2014/921564. Epub 2014 Aug 13.

24. Cho HJ, Oh N, Park JH, Kim KS, Kim HK, Lee E, et al. ZEB1 Collaborates with ELK3 to Repress ECadherin Expression in Triple-Negative Breast Cancer Cells. Mol Cancer Res. 2019; 17(11):22572266. doi: 10.1158/1541-7786.MCR-19-0380. Epub 2019 Sep 11.

25. Wang D, Wang Y, Wu X, Kong X, Li J, Dong C. RNF20 Is Critical for Snail-Mediated E-Cadherin Repression in Human Breast Cancer. Front Oncol. 2020;10:613470. doi: 10.3389/fonc.2020.613470.

26. Bhat-Nakshatri P, Appaiah H, Ballas C, PickFranke $\mathrm{P}$, Goulet $\mathrm{R} \mathrm{Jr}$, Badve $\mathrm{S}$, et al. SLUG/SNAI2, and tumor necrosis factor generate breast cells with CD44+/CD24- phenotype. BMC Cancer 2010; 10:411. doi: 10.1186/1471-2407-10-
411.

27. Edge SB, Compton CC. The American Joint Committee on Cancer: the 7th edition of the AJCC cancer staging manual and the future of TNM. Ann Surg Oncol. 2010; 17(6):1471-1474. doi: 10.1245/s10434-010-0985-4.

28. Hu H, Wei W, Yi X, Xin L, Liu Y. A Retrospective Analysis of Clinical Utility of AJCC 8th Edition Cancer Staging System for Breast Cancer. World J Oncol. 2017; 8(3):71-75. doi: 10.14740/wjon1039e).

29. Alcantara D, Leal MP, García-Bocanegra I, García-Martín ML. Molecular imaging of breast cancer: present and future directions. Front Chem. 2014; 2:112. doi: 10.3389/fchem.2014.00112.

30. Unal I, "Defining an Optimal Cut-Point Value in ROC Analysis: An Alternative Approach". Comput Math Methods Med 2017 17; 3762651. https://doi.org/10.1155/2017/376265 1.

31. Nordstrom L, Andersson E, Kuci V, Gustavsson E, Holm K, Ringer M, et al. DNA methylation and histone modifications regulate SOX11 expression in lymphoid and solid cancer cells. BMC Cancer. 2015; 15:273. doi: 10.1186/s12885-015-1208-y.

32. Sernbo S, Gustavsson E, Brennan DJ, Gallagher WM, Rexhepaj E, Rydnert F, et al. The tumor suppressor SOX11 is associated with improved survival among high grade epithelial ovarian cancers and is regulated by reversible promoter methylation. BMC Cancer. 2011;11:405. doi: 10.1186/1471-2407-11-405.

33. Zhang S, Li S, Gao JL. Promoter methylation status of the tumor suppressor gene SOX11 is associated with cell growth and invasion in nasopharyngeal carcinoma. Cancer Cell Int. 2013; 13(1):109. doi: 10.1186/1475-2867-13-109.

34. Qu Y, Zhou C, Zhang J, Cai Q, Li J, Du T, et al. The metastasis suppressor SOX11 is an independent prognostic factor for improved survival in gastric cancer. Int J Oncol. 2014; 44(5):1512-1520. doi: 10.3892/ijo.2014.2328. Epub 2014 Mar 6. 
35. Yang W, Wang Y, Yu Z, Li Z, An G, Liu W, et al. SOX11 regulates the pro-apoptosis signal pathway and predicts a favorable prognosis of mantle cell lymphoma. Int J Hematol. 2017; 106(2):212-220. doi: 10.1007/s12185-017-2236-y. Epub 2017 Apr 20.

36. Yang Z, Jiang S, Lu C, Ji T, Yang W, Li T, et al. SOX11: friend or foe in tumor prevention and carcinogenesis? Ther Adv Med Oncol. 2019; 11:1758835919853449.

doi: $10.1177 / 1758835919853449$.

37. Liu Z, Zhong Y, Chen YJ, Chen H. SOX11 regulates apoptosis and cell cycle in hepatocellular carcinoma via $\mathrm{Wnt} / \beta$-catenin signaling pathway. Biotechnol Appl Biochem. 2019; 66(2):240-246. doi: 10.1002/bab.1718. Epub 2018 Dec 17.

38. Sarrio D, Perez-Mies B, Hardison D, MorenoBueno G, Suarez A, Cano A, et al. Cytoplasmic localization of p120ctn and E-cadherin loss characterize lobular breast carcinoma from preinvasive to metastatic lesions. Oncogene. 2004; 23(19):3272-3283. doi: 10.1038/SJ.onc.1207439.

39. Thiery JP. Epithelial-mesenchymal transitions in tumor progression. Nat Rev Cancer. 2002; 2(6):442-454. doi: 10.1038/nrc822.

40. Bu JQ, Chen F. TGF- $\beta 1$ promotes cell invasion and migration by inducing epithelial-mesenchymal transformation in oral squamous cell carcinoma. Eur Rev Med Pharmacol Sci. 2017; 21(9):21372144.

41. Howard EM, Lau SK, Lyles RH, Birdsong GG, Umbreit JN, Kochhar R. Expression of e-cadherin in high-risk breast cancer. J Cancer Res Clin Oncol. 2005; 131(1):14-18. doi: 10.1007/s00432004-0618-z. Epub 2004 Oct 1.

42. Cepowicz D, Zareba K, Pryczynicz A, Dawidziuk T, Zurawska J, Hołody-Zareba J, et al. Blood serum levels of E-cadherin in patients with colorectal cancer. Prz Gastroenterol. 2017; 12(3):186-191. doi: 10.5114/pg.2017.70471. Epub 2017 Sep 30.

43. Wang P, Zhu Z. Prognostic and Clinicopathological Significance of E-Cadherin in Pancreatic Cancer Patients: A Meta-Analysis.
Front Oncol. 2021;11:627116. doi: 10.3389/fonc.2021.627116.

44. Liu P, Keller JR, Ortiz M, Tessarollo L, Rachel RA, Nakamura T, et al. Bcl11a is essential for normal lymphoid development. Nat Immunol. 2003; 4(6):525-532. doi: 10.1038/ni925. Epub 2003 Apr 28.

45. Chen YH, Gao J, Fan G, Peterson LC. The nuclear expression of sox 11 is highly associated with mantle cell lymphoma but is independent of $\mathrm{t}(11 ; 14)(\mathrm{q} 13 ; \mathrm{q} 32)$ in non-mantle cell B-cell neoplasms. Mod Pathol. 2010; 23(1):105-112. doi: 10.1038/modpathol.2009.140. Epub 2009 Oct 2.

46. Vegliante MC, Palomero J, Perez-Galan P, Roue G, Castellano G, Navarro A, et al. SOX11 regulates PAX5 expression and blocks terminal $\mathrm{B}$ cell differentiation in aggressive mantle cell lymphoma. Blood. 2013; 121(12):2175-2185. doi: 10.1182/blood-2012-06-438937.

47. Lee BS, Lee BK, Iyer VR, Sleckman BP, Shaffer AL 3rd, Ippolito GC, et al. Corrected and Republished from: BCL11A Is a Critical Component of a Transcriptional Network That Activates RAG Expression and V(D)J Recombination. Mol Cell Biol. 2017; 38(1):e00362-17. doi: 10.1128/mcb.00362-17.

48. Zvelebil M, Oliemuller E, Gao Q, Wansbury O, Mackay A, Kendrick $\mathrm{H}$, et al. Embryonic mammary signature subsets are activated in Brca1/- and basal-like breast cancers. Breast Cancer Res. 2013;15(2): R25. https://doi.org/10.1186/bcr340. 